\title{
The Crucial Role of Policy Surveillance in International Climate Policy
}

\section{Citation}

Aldy, Joseph. 2014. The Crucial Role of Policy Surveillance in International Climate Policy. Climatic Change 126(3-4): 279-292.

\section{Permanent link}

http://nrs.harvard.edu/urn-3:HUL.InstRepos:22509395

\section{Terms of Use}

This article was downloaded from Harvard University's DASH repository, and is made available under the terms and conditions applicable to Other Posted Material, as set forth at http:// nrs.harvard.edu/urn-3:HUL.InstRepos:dash.current.terms-of-use\#LAA

\section{Share Your Story}

The Harvard community has made this article openly available.

Please share how this access benefits you. Submit a story.

\section{Accessibility}




\section{The Crucial Role of Policy Surveillance in International Climate Policy}

Joseph E. Aldy*

Harvard Kennedy School

Resources for the Future

National Bureau of Economic Research

August 15, 2014 Draft

* John F. Kennedy School of Government, Harvard University, 79 JFK Street, Mailbox 57, Cambridge, MA 02138, joseph aldy@hks.harvard.edu, 617-496-7213. 


\section{The Crucial Role of Policy Surveillance in International Climate Policy}

Abstract:

An extensive literature shows that information-creating mechanisms enhance the transparency of and can support participation and compliance in international agreements. This paper draws from game theory, international relations, and legal scholarship to make the case for how transparency through policy surveillance can facilitate more effective international climate change policy architecture. I draw lessons from policy surveillance in multilateral economic, environmental, and national security contexts to inform a critical evaluation of the historic practice of monitoring and reporting under the global climate regime. This assessment focuses on how surveillance produces evidence to inform policy design, enables comparisons of mitigation effort, and illustrates the adequacy of the global effort in climate agreements. I also describe how the institution of policy surveillance can facilitate a variety of climate policy architectures. This evaluation of policy surveillance suggests that transparency is necessary for global climate policy architecture.

Keywords: policy surveillance, climate agreements, monitoring, reporting, compliance 


\section{The Crucial Role of Policy Surveillance in International Climate Policy}

\section{Introduction}

International climate negotiations occur within a system of international relations in which sovereigns maintain significant discretion of action and enjoy substantial deference in their policy decisions. This poses a challenge to designing multilateral agreements and institutions, especially in contexts characterized by strong free-riding incentives such as global climate change. An extensive literature on international agreements shows that information-creating mechanisms enhance the transparency of and can support participation and compliance in such agreements.

This paper draws from game theory, international relations, and legal scholarship to make the case for how transparency through policy surveillance can facilitate more effective multilateral climate agreements. In this paper, policy surveillance refers to the generation and analysis of information on greenhouse gas mitigation policies and programs, including, inter alia, emission levels and estimated reductions, costs and cost-effectiveness, potential cross-border impacts, and ancillary benefits. While information-generating instruments can facilitate multilateral agreements, the status quo system of policy surveillance under the United Nations Framework Convention on Climate Change (UNFCCC) does not provide sufficient information and analysis to meaningfully inform negotiations or characterize progress in mitigating the risks posed by climate change.

To identify potential opportunities for improving climate policy surveillance, I evaluate policy surveillance schemes in other multilateral contexts, including surveillance conducted through the International Monetary Fund (IMF), World Trade Organization (WTO), the Organisation for Economic Co-operation and Development (OECD), the Convention on International Trade in Endangered Species (CITES), and the Montreal Protocol on Ozone-Depleting Substances. I draw out a series of insights and lessons applicable to climate policy surveillance and then describe how a well-designed and implemented system of surveillance could support a variety of climate policy architectures. For example, the international climate negotiations under the Durban Platform for Enhanced Action show increasing interest in architectural elements that depend on some form of surveillance. For example, the procedures for proposing and evaluating commitments - through pledge-and-review and peer review - as well as consideration of some forms of implementation - such as linking of domestic cap-and-trade programs - necessitate enhanced policy surveillance. This assessment of policy surveillance suggests that transparency is necessary for global climate policy architecture.

The next section of this paper synthesizes the literature on how information-producing institutions support agreements. The third section draws lessons from various multilateral systems of policy surveillance. The fourth section details the shortcomings in the current international climate policy framework's transparency mechanisms. The fifth section describes how institutionalizing policy surveillance can serve an array of international climate policy architectures. The final section concludes.

\section{Information and Agreements}


International climate policy attempts to engage nearly 200 countries in addressing a daunting collective action problem characterized by an array of uncertainties. Mitigating greenhouse gas emissions produces a global public good, and thus countries have a strong incentive to deviate from emission mitigation agreements (Barrett 2003). There is uncertainty about the credibility of commitments, reflecting questions on whether a country can implement policies that alter the behavior of private agents (e.g., emission abatement) as well as questions on the ability to observe a country's performance with respect to its commitment. Moreover, uncertainty reflected through exogenous shocks - higher than expected economic growth (e.g., in the United States in the 1990s and China in the 2000s) or energy system disruption (e.g., the Fukushima nuclear disaster in 2011) - also affect incentives for participation and compliance in a multilateral agreement (Hafner-Burton et al. 2012). An extensive academic literature in multiple disciplines illustrates how transparency can reduce uncertainty and mitigate incentives to deviate from an agreement, and thus enable a set of reciprocal actions to deliver on a global public good.

Signaling the seriousness of commitment is often a condition for securing an agreement among parties. Schelling (1956) suggests that transparency and publicity of a party's ex ante pledge and ex post outcome can enhance the credibility of commitments. The "publicity" called for by Schelling can be established by the "information structures" created by the rules of international institutions (Keohane 1998). Transparency mechanisms can facilitate "naming and shaming" and the prospect of adverse reputational consequences for deviating from an agreement may promote compliance (Simmons 1998; Chayes and Chayes 1991). Even without an enforcement mechanism, information-generating institutions may "contain deviance within acceptable levels'" (Klabbers 2007, p. 1004).

Political leaders who push for their nations to take on more ambitious climate change riskreduction policies could benefit from an institution collecting and publicizing information on their actions: it would highlight their leadership on this issue. Policy surveillance provides the information to enable planning ex ante for domestic actions and policies. Such public information also increases the costs to political leaders of failing to deliver on commitments, opening them up to domestic stakeholder pressure and peer pressure from other leaders.

Given the potential net benefits associated with free-riding, some parties may find it in their interest to deviate from an agreement. Barrett (2003) notes the "incentive for parties to deceive creates an incentive for others to monitor" (p. 150). The probability of detecting deviations from an agreement increase with the transparency of the regime, which can thus reassure those countries predisposed to comply and deter those countries considering deviation (Chayes et al. 1998; Levy et al. 1993).

The repeated nature of climate negotiations provides an opportunity for transparency to inform subsequent rounds of negotiations. First, information can promote compliance in repeated games. In his discussion of monitoring in international environmental agreements, Barrett (2003) notes that "transparency is of fundamental importance in a repeated game" (p. 284). Levy et al. (1993) also note that "effective monitoring is a condition for sustained cooperation." In economic policy contexts, Simmons (1998) observes that "[g]reater transparency and opportunities for reciprocity also enhance compliance where there is repeated play within a small group, for example in the European Union or among the large countries in the WTO" ( $p$. 81). Second, structuring iterative negotiations around periodic information collection and 
analysis, could inform the setting of standards, goals, and implementation in subsequent rounds of negotiations, along the lines of Thompson's (2006a) adaptive management scheme for international climate policy.

\section{Lessons on Surveillance from Other International Policy Regimes}

The extensive experience designing and implementing policy surveillance in an array of international policy regimes - including IMF Article IV consultations, OECD economic surveys, the WTO trade policy review mechanism, the Montreal Protocol reporting on ozone-depleting substances, arms control agreements, and the monitoring of trade in endangered species provides a series of lessons applicable to the climate policy context. The information needs and the relevant lessons from these regimes, however, depend on the nature of the commitments in a new climate policy architecture. Coordinating a set of non-binding pledges may require different (and potentially less precise) surveillance than an architecture based on legally-binding emission commitments with enforcement penalties. For example, under the former, surveillance of policy performance - emission reductions, costs, cost-effectiveness - may be important, while a precise estimate of aggregate national emissions - regardless of the efficacy (or even existence!) of domestic mitigation policies - may be the primary objective of surveillance under the latter (e.g., under a Kyoto-style enforcement mechanism). While the stark "bottom-up pledge" versus "top-down binding target" dichotomy may not do justice to the evolving approach to international climate policy, I will employ it to emphasize the relative importance of various lessons from policy surveillance in other regimes.

\subsection{Credibility of Information}

An effective policy surveillance mechanism must produce credible information for use by the parties to international climate agreements. In a wide array of contexts, national governments have effectively delegated such surveillance responsibilities to international organizations, and these entities can play important roles by generating "neutral" information (Thompson 2006b). Chayes et al. (1998) note that "it is no coincidence that the regimes with the most impressive compliance experience - ILO, IMF, OECD, GATT - depend upon substantial, well-staffed, and well-functioning international organizations" (p. 58).

Teams of permanent staff experts make in-country visits as part of policy and data reviews under IMF Article IV consultations and OECD economic policy reviews. (IMF 2001; OECD 2003; Schafer 2006). Under the Trade Policy Review Mechanism, the WTO Secretariat expert team typically visits the country under review and draws from multiple sources - government data, third-party data sources, data in the public domain - in compiling its assessment of the country's trade policy (Mavroidis 1992). Even under the Intermediate Range Nuclear Missile Force Treaty, the United States and the Soviet Union provided for on-site inspection and monitoring (Chayes and Chayes 1991).

An effective transparency mechanism not only collects information, but also provides analysis and evaluation of policy actions and outcomes. Analyzing and disseminating data on countries' actions under an agreement are necessary for transparency to contribute to regime compliance (Chayes et al. 1998). The feasibility of collecting and analyzing information on country participation in an agreement can affect the nature of agreement and the forms of commitments. 
For example, technical limitations to monitoring likely constrained serious arms control talks in the 1950s. As Fearon (1998) notes, it was not until satellite monitoring remedied some of the monitoring barriers in the 1960s that the United States and the Soviet Union engaged in meaningful arms control negotiations. This may suggest the value in designing commitments in terms of pledged policies instead of the outcomes of policies (e.g., emissions). The former are easier to observe than the latter, which can facilitate agreements and review (Schelling 1956). Thompson (2006a) calls for shifting the focus of reporting and review "toward information on successes and failures of various policies and measures implemented at the domestic level" ( $p$. 25).

Victor (2007) calls for a climate change review mechanism based on the IMF model, especially because of its permanent review staff. Aldy (2013) also suggests that a formal institution with permanent staff could implement a transparency mechanism for the global climate policy regime. Such an institutional capacity could provide the confidence in the review mechanism as a function of its credibility, competence, and independence.

\subsection{Engaging Peers}

Expert reviews serve as inputs to a peer review mechanism in IMF, OECD, and WTO surveillance. In the OECD economic survey process, a delegation from the country under review responds to the draft expert report in a meeting of all OECD members. At this meeting, two lead examiners are drawn from the membership of the OECD to initiate the discussion of the draft report's findings and recommendations for policy reforms. The final published report reflects this discussion and must secure agreement among all OECD members before it is completed. Similar processes operate through the WTO Trade Policy Review Body and the IMF Executive Board (IMF 2001; Schafer 2006).

Providing a forum for member states to engage one another through peer review can facilitate learning about effective policy practice and promote understanding about countries' individual policy design and implementation. As a review among peers, the OECD and IMF approaches serve as a facilitative process, not a compliance mechanism, and thus enable more candid dialogue among participants. Schelling (2002) describes the effectiveness of "reciprocal multilateral scrutiny" among government negotiating teams in the talks on the allocation of Marshall Plan resources after World War II. This can serve as an important venue for persuasion to enhance ambition through a pledge and review approach to commitments. It is likely less important in a regime focused $\mathrm{n}$ legally-binding quantitative emission targets.

Based on the OECD model, an effective review process would "allow scrutiny of national policies" (Pizer 2007, p. 309). Pizer suggests annual meetings for discussion of review, provision of feedback, and opportunities to adjust commitments. The UNFCCC review process does not include a formal peer review mechanism, although the system of international consultations and analysis initially established in the 2009 Copenhagen Accord could provide for a consultative process among peers.

\subsection{Learning}


Levy et al. (1993) note that international policy surveillance institutions can "foster capacitybuilding by providing policy-relevant information in a form that is readily usable" (p. 415). The UNFCCC has adopted IPCC guidelines for emission inventories and land use, land use-change, and forestry (IPCC 2003). Best practices could extend beyond emission accounting to include policies. Aldy (2013) notes that identifying best practice policies through the experiences of countries undertaking emission mitigation can provide important information for developing countries as they design their mitigation programs.

Developed and emerging economies have substantial experience in implementing policies that can affect the investment in low-carbon technologies. Drawing lessons from these successes and failures can inform the design of new policies in all countries, but especially those in developing countries that may lack the institutional capacity to fully evaluate policy options. Establishing a set of "best practice" policies can draw from past efforts to promote the deployment of low-carbon technologies, and tailor guidance for countries' specific economic and cultural circumstances. As some developing countries become expert on adaptation, they can export best adaptation practices.

Understanding the aggregate impact of all nations' greenhouse gas mitigation policies is critical to evaluating the overall efficacy of the international climate policy architecture. Chayes et al. (1998) note that "creating transparency in international treaties generates information for assessing compliance of individual parties as well as evaluating overall regime effectiveness" ( $p$. 49). The IMF conducts regular surveillance of the global economy -an assessment of the aggregate impact of economic, monetary, and fiscal policies of the member countries - and publishes the World Economic Outlook typically twice per year. Indeed, it is similar experience in trade policy that motivates Victor's (2007) proposal to include an assessment of the collective consequence of individual country efforts in a climate change transparency regime.

For example, global climate policy reviews could draw from annual reporting of greenhouse gas emissions from every country, the policy surveillance undertaken that year, as well as thematic analyses. These reviews would also provide near-term forecasts for greenhouse-gas emissions growth and identify policy reforms that could reduce emissions. Doing so would provide a rigorous benchmark for the review of the adequacy of effort called for under the UNFCCC. This could build on current efforts by the International Energy Agency through its World Energy Outlooks, UNEP through its Emissions Gap reports, and Ecofys through its Climate Action Tracker (http://climateactiontracker.org/). It is important that such a global review address aggregate emissions, which is the focus of these existing third-party reviews, and policy effectiveness, costs, etc. that typically receive less attention. These reviews could also include recommendations of best policies appropriate to the geographic, cultural, and economic context of specific countries.

\subsection{Implementing Surveillance}

The IMF supports standards for data dissemination and codes for good policy practice that facilitates annual surveillance and benefits member countries in their implementation of economic policy. Implementing these standards has "enhance[d] the technical and professional capacities of finance ministries and central banks" (Chayes et al. 1998, p. 53). The WTO, WHO, FAO, and WMO provide technical assistance to developing countries as a primary programmatic activity (Chayes et al. 1998). 
The Secretariat to the Montreal Protocol on Ozone Depleting Substances (ODS) facilitated developing-country reporting by elaborating procedures for tracking and reporting ODS data, providing data reporting templates, and explaining ways to improve domestic monitoring. The Montreal Protocol increased the costs for failing to submit adequate ODS data reports by linking access to financing for projects to reduce ODS consumption to satisfying the reporting requirements (Wettestad 2007).

International institutions of information collection and dissemination can lower the costs of an international agreement. Technical and financial assistance for key elements of capacity building could enable improved monitoring, reporting, and evaluation in developing countries (Keohane 1994). International institutions can formally undertake monitoring that lowers the transaction costs of an agreement. The provision of standards and reporting templates can improve the transparency of the reporting and review and enhance surveillance effectiveness. Given the weak (or non-existent) domestic climate policy surveillance institutions in many developing countries, a robust international system of transparency will require improving the technical capacity in many countries to adequately monitor and report on their domestic climate policy activities (MacFaul 2006). This may require additional resources for data collection and reporting standards, analytic tools, personnel training, and surveillance implementation.

The OECD facilitates reviews of member states' economic policies every one to two years (OECD 2003; Schafer 2006). IMF Article IV consultations typically occur annually and apply to all IMF members. WTO members are subject to a regular review of their trade policies (Mavroidis 1992). The four countries with the largest share of world trade undergo policy review every two years, while the next sixteen participate in reviews four years, and all other countries take part in reviews every six years. The frequency of individual country policy reviews could vary with the level of current greenhouse gas emissions, like the WTO review process.

\subsection{The Role for Civil Society}

Shining a light on policy implementation and outcomes can empower stakeholders and members of civil society. For example, making public Article IV consultations enables stakeholders to push for better economic policies in their respective countries and improves the quality of the IMF review product by subjecting the reviewers to external assessment (Fischer 1999). Requiring transparency and permitting civil society scrutiny can enhance the accountability of an international agreement (Keohane 1998). Nongovernmental organizations have provided information to challenge claims made by some countries in the reporting of their human rights policies and practices (Chayes et al. 1998). The Convention on International Trade in Endangered Species formally relies on international nongovernmental organizations - the World Conservation Union and the World Wildlife Fund - to provide independent reviews of national reports and a trade monitoring network (Wettestad 2007). Individual counties have increased transparency by making data available, such as the public dissemination of satellite data on Amazonian forest cover by the Government of Brazil. ${ }^{1}$ Public dissemination of emissions data and policy evaluation can enable nongovernmental organizations to contribute more effectively to domestic policy design and international negotiations.

\footnotetext{
${ }^{1}$ Satellite imaging data can be accessed at http://www.dgi.inpe.br/CDSR/.
} 


\section{The Status Quo Global Climate Change Policy Surveillance Regime}

An effective transparency institution would provide information and evidence to inform the design of global climate policy, enable a credible analysis of the comparability of effort among participating parties and thus illustrate reciprocity of action, and demonstrate the aggregate impacts of participating countries' actions on the global climate. This section reviews and describes the shortcomings of the UNFCCC transparency system along these three dimensions.

\subsection{The Role of Evidence and Credible Information in Climate Policy}

The current international climate change policy architecture suffers from a dearth of information on countries' contributions to climate change risk mitigation. Under Article 12 of the UNFCCC, Annex I countries submit annual greenhouse gas emission inventories while NonAnnex I countries submit infrequent emission inventories - most developing countries have reported no more than two years of emissions data since 1992 (Breidenich and Bodansky 2009). For example, China submitted information on its greenhouse gas emission inventory for 1994 (in its 2004 national report) and for 2004 (in its 2012 national report). A once-per decade snapshot of emissions, with nearly a decade-long reporting lag, is clearly inadequate to inform policy especially given independent estimates indicating that Chinese fossil carbon emissions were 68\% greater than U.S. emissions in 2011 (Le Quéré et al. 2013). In addition, nations communicate to the UN reports on their climate change vulnerability, climate change policies, greenhouse gas emissions, and related topics under Article 12 of the Convention. Industrialized countries each submitted five national reports to the UNFCCC through 2012, while developing countries submitted no more than two reports over this time frame.

Given this information vacuum, north-south rhetoric, as opposed to evidence, has informed the implementation of UNFCCC principles, such as "common but differentiated responsibilities and respective capabilities." For example, the 1995 Berlin Mandate, which culminated in binding emission targets for industrialized countries in the Kyoto Protocol, notes that this negotiating process "shall be guided" in part by "the fact that the largest share of historical and current global emissions of greenhouse gases has originated in developed countries." ${ }^{2}$ The "fact" that the "largest share of current global greenhouse gas emissions originated in developed countries" is not correct. Data published in a 1993 issue of Climatic Change show that the largest share of 1988 global emissions of greenhouse gases originated in the developing countries referred to as Non-Annex B countries under the Kyoto Protocol (Subak et al. 1993)., 4

\footnotetext{
${ }^{2}$ Emphasis added. Available online at: http://unfccc.int/resource/docs/cop1/07a01.pdf.

${ }^{3}$ Subak et al. (1993) published data on $\mathrm{CO}_{2}, \mathrm{CH}_{4}$, and $\mathrm{N}_{2} \mathrm{O}$ emissions for 142 countries. I constructed the Annex $B$ aggregate from the paper's appendix, which omits two very small Annex B nations (Monaco and Liechtenstein) and includes 15 Non-Annex B countries in the calculation of Annex B aggregate emissions (circa 1988 Soviet Union and Yugoslavia are included among these Non-Annex B countries). Non-Annex B emissions are constructed as the difference between the reported world emissions and this Annex B aggregate estimate.

"I use the terms "Annex B" and "Annex I" interchangeably to represent industrialized countries since their memberships are nearly identical.
} 
The Berlin Mandate suggests that countries' contemporaneous share of global emissions should inform commitments. Unfortunately, there is no UNFCCC monitoring or reporting mechanism to provide information on developed and developing countries' respective share of global greenhouse gas emissions in a recent year. Independent estimates of annual carbon dioxide $\left(\mathrm{CO}_{2}\right)$ emissions from fossil fuel combustion show that the developing country share has grown each year since 1988 and comprised 60\% of global fossil carbon emissions in 2011 (Le Quéré et al. 2013). ${ }^{5}$

The global climate regime also recognizes countries" "respective capabilities" as a principle to guide policy action. It is difficult to reconcile the "differentiation" in emission reporting - i.e., no reporting for the developing countries responsible for more than three-fifths of current global emissions - with respective capabilities. First, note that developing countries have the capacity to report annual detailed inventory data under the Montreal Protocol. Second, many developing countries have greater capacity than at least some of the industrialized countries that have annual UNFCCC emission reporting requirements. About 50 Non-Annex I countries have higher per capita incomes than the poorest Annex I country. In addition, about 40 Non-Annex I countries rank higher on the Human Development Index than the lowest-ranked Annex I country (Aldy and Stavins 2012).

There is, nonetheless, substantial heterogeneity among Non-Annex I countries. Some developing countries lack the institutional capacity to monitor emissions, evaluate programs and policies, estimate emission reductions across various sources and sectors in their economies, and report this information. For example, the 2013 UNEP “Emissions Gap" report notes that "serious information gaps preclude comprehensive assessment of several countries' emission trajectories under current policies" (p. 12).

The differentiation in monitoring occurs in the frequency and quality of reporting and review. Developed countries submit annual emission reports, pursuant to established guidelines subject to expert review. In contrast, developing countries emissions reports are made as a part of their infrequent national reports, and are neither subject to the same data standards as developed countries nor undergo expert review (Breidenich and Bodansky 2009; MacFaul 2006). Even the regular reporting of developed countries emissions is insufficient to characterize the effectiveness of emission mitigation actions in these countries (Ellis and Larsen 2008; Breidenich and Bodansky 2009; Thompson 2006a). The reviews of industrialized countries typically draw, in an ad hoc nature, from government-sponsored experts (from academia, business, and government sectors) to conduct a review, with occasional in-country visits, as opposed to relying on a professional bureaucracy.

\subsection{Comparability of Effort}

In order for a set of countries to perceive their contribution to mitigating climate change as fair, they need information to assess the comparability of effort. ${ }^{6}$ The absence of credible, legitimate

\footnotetext{
${ }^{5}$ Since developing countries have traditionally had a larger share of land use $\mathrm{CO}_{2}$ and methane emissions, their share of total global greenhouse gas emissions in 2011 may well approach two-thirds. The absence of a credible monitoring regime complicates this assessment.

${ }^{6}$ Refer to Aldy and Pizer (2014) for a detailed discussion of metrics for comparing mitigation effort among parties to the UNFCCC.
} 
means for comparing effort affects the determination of the set of countries that take on commitments, the ex ante assessment of countries' proposed commitments, and the ex post evaluation of countries' performance in delivering on those commitments. Indeed, a formal process to engage peers in the review of other countries' actions, policies, and emission outcomes would naturally lead to an assessment of the comparability of effort.

The traditional way to compare mitigation commitments has been to focus on a country's commitment relative to its 1990 emission level. Yet, emissions are an outcome, often of many factors in addition to domestic emission mitigation policies, not a measure of effort. For example, the shutting down of old Soviet industrial infrastructure and the transformation from planned to market economies has resulted in dramatic emission reductions. Since the UNFCCC entered into force in 1994, Russia's greenhouse gas emissions have never exceeded $60 \%$ of their 1990 level (the emission target Russia agreed to in the Kyoto Protocol). Comparing current emissions to any historic level of emissions provides a very noisy signal of effort. The current system of periodic national reports is so incomplete and inconsistent that it is not possible to credibly compare effort among countries or even compare effort within a country over time (Thompson 2006a).

Assessing the comparability of effort became more challenging with the myriad forms of emission commitments under the Copenhagen Accord and Cancun Agreements - emission targets relative to a base year, emission reductions relative to a business-as-usual forecast, improvement in the emission-to-GDP ratio, as well as sector-specific policies and goals. There was no transparency mechanism to evaluate and compare these proposed commitments in the lead up to the Copenhagen talks. ${ }^{7}$ This yields several adverse consequences for the negotiations.

First, only the largest and most advanced governments have the capacity to evaluate other countries' proposals, thus putting smaller, less developed countries at a negotiating disadvantage. Second, the small set of countries that can assess others' proposals may shape or censor information dissemination consistent with their negotiating strategies. Third, there may be no comprehensive evaluation of proposed commitments. ${ }^{8}$ Fourth, views on a specific proposal may differ and thus create confusion in the negotiations. For example, was China's 2009 proposal to lower its $\mathrm{CO}_{2}$-to-GDP intensity 40-45\% through 2020 an ambitious gamechanger or just continuing along business-as-usual? The determination may depend on resolving an important ambiguity in China's proposal - how is GDP measured in the intensity calculation nominal, constant-year Yuan, or real purchasing power parity? If nominal GDP is used, then this improvement is less ambitious than historic trends (Aldy and Pizer 2014). These are potentially

\footnotetext{
${ }^{7}$ Nearly a year after the Copenhagen talks, the United Nations Environment Programme (2010) produced the first of a series of "emissions gap" reports that estimated the emission impacts of countries' Copenhagen Accord emission goals, policies, and actions, most of which were incorporated in the Cancun Agreements. This report focused on the aggregate impact of the pledged emission commitments, and paid less attention to the comparability of commitments. In 2012, as a part of the Cancun Agreements (Decision 1/CP.16, paragraph 38), the UNFCCC secretariat organized a workshop to clarify the assumptions and expected outcomes of Annex I emission pledges through 2020. Some countries appear to have approached this "clarification" process as an opportunity to increase information flow and enhance transparency, while others have approached this as an opportunity to push for more ambitious emission mitigation commitments.

${ }^{8}$ The UNEP "gap reports" provide some information on country emission pledges, especially with respect to emission levels, but focus less attention on design, implementation, efficacy, and costs of policies.
} 
important questions to which a transparency mechanism could focus attention, instead of the ad hoc manner of the status quo.

\subsection{Adequacy of Global Effort}

The UNFCCC surveillance program does not report global aggregate greenhouse gas emissions. There is neither a reporting nor a monitoring mechanism that would even permit a UNFCCC global emission estimate. This undermines the ability of participating governments and interested stakeholders to learn about the efficacy of the multilateral climate policy regime. For a global treaty focused on near-term emission commitments and long-term atmospheric greenhouse gas concentration stabilization, and under which the Cancun Agreements called for peaking in global emissions as soon as possible (Decision 1/CP16, paragraph 6), it is striking that it does not track the flow of global emissions.

Independent estimates of fossil fuel $\mathrm{CO}_{2}$ emissions provide little evidence that the UNFCCC has delivered adequate effort. Global fossil carbon emissions in 2011 were more than $50 \%$ greater than they were in 1992 (Le Quéré et al. 2013). Global emissions grew about 2.8\% annually in the decade after the Kyoto negotiations, dramatically faster than the $1.2 \%$ annual rate in the decade leading up to the Kyoto Conference.

There are many voices in the academic and advocacy communities who have noted that current actions are inadequate (e.g., UNEP 2010, 2013). It is difficult to have a serious, productive negotiation on "how to close the ambition gap" when there is neither agreement on a global emission goal (a normative question) nor information of global emissions (a positive and technical question that could be addressed through the design, financial support of, and application of data collection protocols throughout the world). As a result, the negotiations lack an easily observable measure of progress that could facilitate subsequent rounds of negotiations.

\section{Integration with Climate Policy Architectures}

Drawing on the international climate policy architecture classifications in Aldy and Stavins (2007), this section illustrates the role that policy surveillance could play in targets and timetables, harmonized domestic actions, and coordinated and unilateral policies architectures.

\subsection{Targets and Timetables}

Under Kyoto-style quantitative emission targets, the primary role for policy surveillance would be to "count the tons." The review of emissions data would demonstrate whether a country is incompliance with its emission target. The surveillance could also play a role in informing the setting of targets. For example, Frankel (2010) proposes to set emission targets as a function of incomes, historic emissions, and per capita emissions, i.e. quantitative measures of ability to pay, responsibility, and equity.

\subsection{Harmonized Domestic Actions}

Harmonized domestic actions could be legally-binding or reflect explicit coordination of common pledged policies, and thus the surveillance demands would defer by the legal nature of 
the commitment. Consider the two most commonly advocated instruments of implementation, a carbon tax and cap-and-trade. Cooper (2010) calls for harmonized domestic $\mathrm{CO}_{2}$ taxes as the basis for an international climate policy regime. In his proposal, the IMF would review countries' carbon taxes. A system of policy surveillance could ensure that economic activity around the world faces a common carbon price, including evaluation of any efforts at fiscal cushioning and evaluate the effectiveness of $\mathrm{CO}_{2}$ tax policies.

A number of countries and regions have linked their domestic cap-and-trade programs (e.g., the EU and Norway, California and Quebec), and future linking could serve as part of a global climate policy architecture (Jaffe and Stavins 2010). The linking of any two programs would likely involve a mutual assessment to ensure comparable integrity. For example, California and Quebec established a consultation committee to monitor the implementation of their linked programs (California Air Resources Board 2013). Domestic stakeholders in each system may demand surveillance and a consultative process. The transparency mechanism of an international climate regime could inform this evaluation for any two cap-and-trade programs considering linking.

\subsection{Coordinated and Unilateral Policies}

Policy surveillance would play a critical role as the "review" element of bottom-up climate-policy pledge-implement-review schemes (Schelling 2002; Pizer 2007; Victor 2007). For example, the pledge and review system reflected in the Copenhagen Accord and the Cancun Agreements would certainly benefit from a rigorous review program. This is evident in the agreement for "international consultations and analysis" of developing country mitigation actions, policies, and goals as well as in the assessment of international climate finance. If these review mechanisms are well-designed and employed in practice, then the reviews could assess whether countries fully implemented their pledges and determine the effectiveness of various policy approaches to reduce emissions. In this case, the ex post policy surveillance of a round of commitments can inform negotiations over the subsequent round of commitments.

Policy surveillance could inform commitments within a given round of talks through a "pledgereview-repledge" system. In this case, the negotiations occur in three parts. First, countries propose or pledge commitments. Second, the policy surveillance mechanism undertakes an ex ante review of the proposed commitments. Finally, countries negotiate over the final commitments in which the analysis produced by the review mechanism could inform the final agreement.

Finally, policy surveillance could inform unilateral domestic policies such as a border carbon tax. A neutral evaluation of a given country's climate program could serve as the basis for assessing whether that country merits a waiver from another country's border tax. Analysis of domestic policy actions among a set of trade partners, including a formal assessment of the comparability of effort, could inform these domestic actions on border measures and allow for an evidencebased determination of the border measure's consistency with the WTO's non-discriminatory application standard.

\section{Conclusions}


A rigorous transparency regime focused on the policies designed to mitigate the risks of climate change is necessary for a successful international climate change agreement. Compiling and analyzing information on climate change policies can provide a robust evidentiary basis for the global climate framework, provide information on the comparability of effort that can facilitate trust and agreement among countries, and identify the adequacy of the collective effort to combat climate change. This paper illustrates how transparency could facilitate the operation of an array of policy architectures. Let me close with comments on the institutional design of a transparency mechanism and the objective for policy and regime learning under a climate change policy framework.

In another paper, I have called for creating a Bretton Woods Climate Institution (Aldy 2013). Such an institution would have a permanent, professional bureaucracy focused on policy surveillance. This institution could undertake the regular reviews of countries' climate change policies and associated outcomes, host periodic consultative peer reviews among member states, compile assessments of the collective impact of policy actions, synthesize the results of reviews through policy guidance, provide technical assistance to lower-income countries, and identify and disseminate information collection and analysis standards to participating countries. It could be governed by an executive board that reflects the contributions to the institution and geographic diversity, which would meet regularly to discuss the draft reports by the expert review teams. Given the importance of the challenge posed by climate change, investing resources in a policy surveillance mechanism like this Bretton Woods Climate Institution would improve the rigor and robustness of policy evaluation and put climate change policy on par with economic and trade matters in the international arena.

Finally, the international effort to combat climate change would benefit from an understanding of the benefits of: (1) an incremental dollar expended on mitigation; (2) an incremental dollar expended on adaptation; and (3) an incremental dollar expended on geoengineering. A robust transparency regime can facilitate the learning necessary to provide the understanding of the relative returns to various approaches to mitigating climate change risk. Absent this knowledge, it will be quite challenging to structure international climate change agreements and design domestic policy efforts that can efficaciously and cost-effectively address climate change.

\section{Acknowledgments}

Scott Barrett, Roger Fouquet, Bard Harstad, Trevor Houser, Jonathan Pershing, Billy Pizer, Rob Stavins, Rob Stowe, three referees and the editor, and participants at the 2008 Third Atlantic Workshop on Energy and Environmental Economics provided comments on an earlier version of this paper. Sarah Cannon, Napat Jatusripitak, Ryan Powell, and Sarah Szambelan provided valuable research assistance. Support for this work has been provided by the Harvard Project on Climate Agreements. 


\section{References}

Aldy, Joseph E. 2013. "Designing a Bretton Woods Institution to Address Global Climate Change." In: Fouquet, Roger, ed. Handbook of Energy and Climate Change. Cheltenham, UK: Edward Elgar.

Aldy, Joseph E. and William A. Pizer. 2014. "Comparability of Effort in International Climate Policy Architecture." Harvard Project on Climate Agreements Discussion Paper 14-62.

Aldy, Joseph E. and Robert N. Stavins. 2012. "Climate Negotiators Create an Opportunity for Scholars." Science 337: 1043-1044.

Aldy, Joseph E. and Robert N. Stavins. 2007. Architectures for Agreement: Addressing Global Climate Change in the Post-Kyoto World. Cambridge: Cambridge University Press.

Barrett, Scott. 2003. Environment and Statecraft: The Strategy of Environmental TreatyMaking. Oxford: Oxford University Press.

Breidenich, Clare and Daniel Bodansky. 2009. Measurement, Reporting and Verification in a Post-2012 Climate Agreement. Pew Center on Global Climate Change Report, April. Arlington, VA: Pew Center.

California Air Resources Board. 2013. Agreement between the California Air Resources Board and the Gouvernement du Quebec concerning the Harmonization and Integration of Cap-andTrade Programs for Reducing Greenhouse Gas Emissions. September.

Chayes, Abram and Antonia Handler Chayes. 1991. "Compliance without Enforcement: State Behavior under Regulatory Treaties." Negotiation Journal 7(3): 311-330.

Chayes, Abram, Antonia Handler Chayes, and Ronald B. Mitchell. 1998. "Managing Compliance: A Comparative Perspective." In: Edith Brown Weiss and Harold Jacobson, eds. Engaging Countries: Compliance with International Environmental Accords. Cambridge: MIT Press.

Cooper, Richard N. 2010. "The Case for Charges on Greenhouse Gases." In: J.E. Aldy and R.N. Stavins, eds., Post-Kyoto International Climate Policy: Implementing Architectures for Agreement. Cambridge: Cambridge University Press.

Ellis, Jane and Kate Larsen. 2008. Measurement, Reporting, and Verification of Mitigation Actions and Commitments. OECD and IEA Publication COM/ENV/EPOC/IEA/SLT(2008)1. Paris: OECD and IEA.

Fearon, James D. 1998. "Bargaining, Enforcement, and International Cooperation." International Organization 52(2): 269-305.

Fischer, Stanley. 1999. "Reforming the International Financial System." The Economic Journal 109: F557-F576. 
Frankel, Jeffrey. 2010. "An Elaborated Proposal for a Global Climate Policy Architecture: Specific Formulas and Emission Targets for All Countries in All Decades." In: J.E. Aldy and R.N. Stavins, eds., Post-Kyoto International Climate Policy: Implementing Architectures for Agreement.

Cambridge: Cambridge University Press.

Hafner-Burton, Emilie M., David G. Victor, and Yonatan Lupu. 2012. "Political Science Research on International Law: The State of the Field." American Journal of International Law 106: 47-97.

IMF. 2001. Annual Report 2001. Washington, DC: IMF.

IPCC. 2003. Good Practice Guidance for Land Use, Land-Use Change, and Forestry. IPCC National Greenhouse Gas Inventories Programme, Technical Support Unit.

Jaffe, Judson and Robert N. Stavins. 2010. "Linkage of Tradable Permit Systems in International Climate Policy Architecture." In: J.E. Aldy and R.N. Stavins, eds., Post-Kyoto International Climate Policy: Implementing Architectures for Agreement. Cambridge: Cambridge University Press.

Keohane, R.O. 1994. "Against Hierarchy: An Institutional Approach to International Environmental Protection." In: Complex Cooperation: Institutions and Processes in International Resource Management. Oslo: Scandinavian University Press.

Keohane, Robert O. 1998. "International Institutions: Can Interdependence Work?" Foreign Policy (110): 82-96.

Klabbers, Jan. 2007. "Compliance Procedures.” In: Bodansky, Daniel, Jutta Brunee, and Ellen Hey, eds. The Oxford Handbook of International Environmental Law, Oxford: Oxford University Press, 995-1009.

Le Quéré, C. et al. “The Global Carbon Budget 1959-2011." Earth System Science Data 5: 165185.

Levy, Marc A., Robert O. Keohane, and Peter M. Haas. 1993. "Improving the Effectiveness of International Environmental Institutions." In: Haas, P.R., R.O. Keohane, and M.A. Levy, eds. Institutions for the Earth: Sources of Effective International Environmental Protection. Cambridge: MIT Press.

MacFaul, Larry. 2006. "Developing the Climate Change Regime: The Role of Verification." In: Rudolf Avenhaus, Nicholas Kyriakopoulos, Michel Richard, and Gotthard Stein, eds. Verifying Treaty Compliance. Springer, 171-209.

Mavroidis, P.C. 1992. "Surveillance Schemes: The GATT's New Trade Policy Review Mechanism." Michigan Journal of International Law 13: 374-414.

OECD. 2003. Peer Review: A Tool for Co-operation and Change. OECD Policy Brief. December.

Pizer, William A. 2007. "Practical Global Climate Policy." In: In: J.E. Aldy and R.N. Stavins, eds., Architectures for Agreement: Addressing Global Climate Change in the Post-Kyoto World. Cambridge: Cambridge University Press. 
Schafer, A. 2006. "A New Form of Governance? Comparing the Open Method of Co-ordination to Multilateral Surveillance by the IMF and the OECD." Journal European Public Policy 13(1): 7088.

Schelling, Thomas C. 1956. “An Essay on Bargaining.” American Economic Review 46(3): 281-306.

Schelling, Thomas C. 2002. "What Makes Greenhouse Sense?" Foreign Affairs 81(3): 2-9.

Simmons, Beth A. 1998. "Compliance with International Agreements." Annual Review of Political Science 1: 75-93.

Subak, Susan, Paul Raskin, and David von Hippel. 1993. "National Greenhouse Gas Accounts: Current Anthropogenic Sources and Sinks." Climatic Change 25: 15-58.

Thompson, Alexander. 2006a. "Management Under Anarchy: The International Politics of Climate Change." Climatic Change 78: 7-29.

Thompson, Alexander. 2006b. "Screening Power: International Organizations as Informative Agents." In: Hawkins, Darren G., David A. Lake, Daniel L. Nielson, and Michael J. Tierney, eds. Delegation and Agency in International Organizations. Cambridge: Cambridge University Press.

United Nations Environment Programme. 2010. The Emissions Gap Report: Are the Copenhagen Accord Pledges Sufficient to Limit Global Warming to $2^{\circ} \mathrm{C}$ or $1.5^{\circ} \mathrm{C}$ ? November.

United Nations Environment Programme. 2013. The Emissions Gap Report 2013. November.

Victor, David G. 2007. "Fragmented Carbon Markets and Reluctant Nations: Implications for the Design of Effective Architectures." In: In: J.E. Aldy and R.N. Stavins, eds., Architectures for Agreement: Addressing Global Climate Change in the Post-Kyoto World. Cambridge: Cambridge University Press.

Wettestad, Jorgen. 2007. "Monitoring and Verification." In: Bodansky, Daniel, Jutta Brunee, and Ellen Hey, eds. The Oxford Handbook of International Environmental Law, Oxford: Oxford University Press, 974-994. 